\begin{tabular}{|lcl}
\hline REVISTA & NARRAIVAS \\
DA \\
FUNDARTE
\end{tabular}

\title{
NARRATIVAS DE CRIANÇAS SOBRE A CIDADE: PENSAMENTO ESTÉTICO, POLÍTICA E CIDADANIA
}

\author{
Maria Andreza Costa Barbosa \\ Maria Lídia Bueno Fernandes
}

DOI: $10.19179 / 2319-0868.805$

BARBOSA, Maria Andreza Costa. FERNANDES, Maria Lídia Bueno. Narrativas de crianças sobre a cidade: pensamento estético, política e cidadania. Revista da FUNDARTE. Montenegro, p.01-18, ano 20, № 42, julho/setembro de 2020.

Disponível em: http://.seer.fundarte.rs.gov.br/index.php/RevistadaFundarte/index> 30 de setembro de 2020 


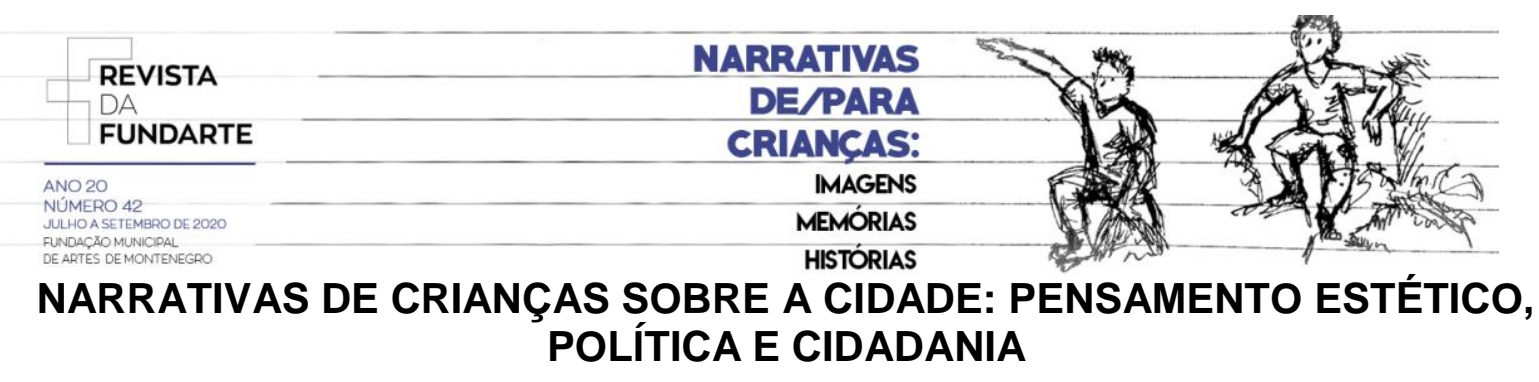

Maria Andreza Costa Barbosa ${ }^{1}$ Maria Lídia Bueno Fernandes²

Resumo: O presente artigo desenvolvido no âmbito do Grupo de Pesquisa Sujeitos, Territórios e a Construção do Conhecimento da Faculdade de Educação da Universidade de Brasília busca respostas acerca da constituição humana no processo de apropriação da cultura, bem como do significado de estar inserido em um contexto cultural, fortemente definido pelo espaço-tempo. Consideram-se as singularidades das crianças de diferentes Regiões Administrativas do Distrito Federal, levando em conta as especificidades desse território, as relações de poder estabelecidas, bem como as múltiplas formas de apropriação, circulação e transformação do/no território. Os pressupostos teóricos ancoram-se nos estudos sociais da infância (LOPES; FERNANDES, 2018) e na Teoria Histórico-Cultural de Vigotski (2010). Considera-se que a cidade nos permite refletir sobre o cotidiano dos sujeitos com atenção às imagens e às referências que se formam por meio da organização espacial, da sociabilidade, da segregação social e espacial, dos deslocamentos, da paisagem e da diversidade cultural.

Palavras-chave: Infância; Território; Distrito Federal do Brasil.

\section{RECITS D'ENFANTS SUR LA VILLE : PENSÉE ESTHÉTIQUE, POLITIQUE ET CITOYENNETÉ}

Résumé: Cet article développé dans le cadre du Groupe de Recherche Sujets, des Territoires et de la construction de la Connaissance de la Faculté d'Éducation de l'Université de Brasília cherche des réponses à propôs de la constitution humaine dans le processus d'appropriation de la culture, ainsi que le sens d'être inséré dans un contexte culturel, fortement défini par l'espace-temps. Les

1 Mestre em Educação pela Universidade de Brasília (2018), pós-Graduação Lato Sensu em História da Arte e Arquitetura no Brasil pela Pontifícia Universidade Católica PUC/RJ (1995) e graduação em Educação Artística pela Faculdade de Artes/Fundação Brasileira de Teatro Dulcina de Morais (1991). Professora na Secretaria do Estado de Educação do DF-SEEDF desde 1998. Trabalhou na elaboração de políticas públicas para a educação integral e em projetos para implementação de Escolas Parque e Centros Interescolares de Línguas no DF;

2 Doutora em Geografia pela Universidade de São Paulo - USP (2009), graduada e licenciada em Geografia pela USP (1987). Magister Artium em Etnologia e Psicologia Social pela LudwigMaximilians-Universität de Munique, Alemanha (1997). Professora da Faculdade de Educação e do Programa de Pós-Graduação em Educação - PPGE da Universidade de Brasília - UnB. Pósdoutorado na Universidade Federal Fluminense. Membro da Rede de Investigação Multidisciplinar sobre Protagonismo e Direitos Humanos das Infâncias; da Rede de Estudos Rurais em Família, Infância e Juventude e da Red Latinoamericana de Investigación y reflexión con niñas, niños y jóvenes.

BARBOSA, Maria Andreza Costa. FERNANDES, Maria Lídia Bueno. Narrativas de crianças sobre a cidade: pensamento estético, política e cidadania. Revista da FUNDARTE. Montenegro, p.01-18, ano 20, no 42, julho/setembro de 2020.

Disponível em: http://.seer.fundarte.rs.gov.br/index.php/RevistadaFundarte/index> 30 de setembro de 2020 


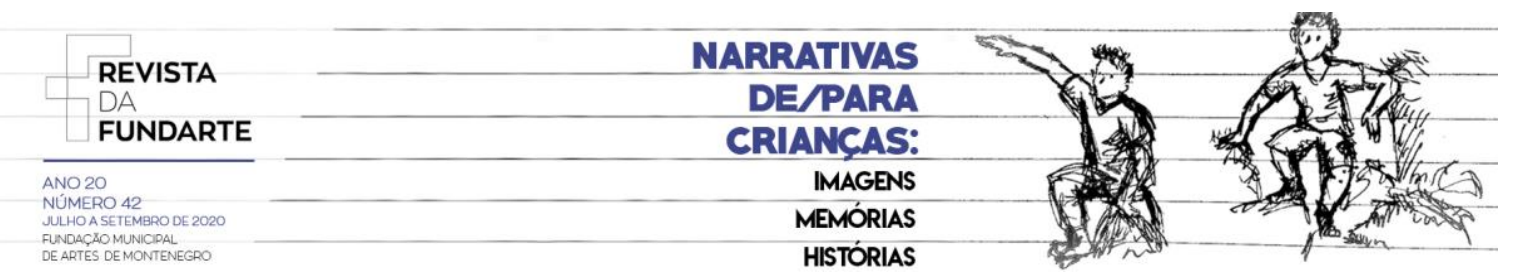

singularités des enfants de différentes régions administratives du District Fédéral ont été prises en compte, en tant que des spécificités de ce territoire, des relations de pouvoir établies, ainsi que des multiples formes de propriété, circulation et transformation du/dans le territoire. Les hypothèses théoriques sont ancrées dans les études sociales de l'enfance (LOPES; FERNANDES, 2018) et la Théorie historique-culturelle (VIGOTSKI, 2010). La ville, cependant, nous a fait réfléchir sur la vie quotidienne des sujets avec une attention aux images et aux références qui sont formées par l'organisation spatiale, la sociabilité, la ségrégation sociale et spatiale, le déplacement, le paysage et la diversité culturelle.

Mots-clés: Enfance, Territoire, District Fédéral du Brésil

\title{
CHILDREN'S NARRATIVES ABOUT THE CITY: AESTHETIC THINKING, POLITICS AND CITIZENSHIP
}

\begin{abstract}
This article developed in the framework of the Group of Research Subjects, Territories and the construction of Knowledge of the Faculty of Education of the University of Brasilia seeks answers about the human constitution in the process of appropriation of culture, as well as the meaning of being inserted in a cultural context, strongly defined by space-time. Children's singularities in different regions of the Federal District are taken into account, as well as the specificities of the territory, the established power relations, as well as the multiple forms of appropriation, circulation and transformation of the territory. The theoretical assumptions are anchored in the social studies of childhood (LOPES; FERNANDES, 2018) and in the Historical-Cultural Theory of Vygotsky (2010). It is considered that the city allow us reflect on the daily life of subjects with attention to the images and references that are formed through spatial organization, sociability, social and spatial segregation, displacements, landscape and cultural diversity.
\end{abstract}

Key-words: Childhood, Territory, Federal District of Brazil.

\section{Introdução}

O presente artigo apresenta um recorte de uma pesquisa maior denominada "Narrativas e saberes dos sujeitos em relação ao território: o Distrito Federal como tema" desenvolvida no âmbito do Grupo de Pesquisa Sujeitos, Territórios e a Construção do Conhecimento da Faculdade de Educação da Universidade de Brasília. Essa pesquisa guarda-chuva busca respostas acerca da constituição humana no processo de apropriação da cultura, bem como do significado de estar inserido em um contexto cultural, fortemente definido pelo espaço-tempo, que, ao mesmo tempo em que nos constitui é igualmente por nós constituído, em um

BARBOSA, Maria Andreza Costa. FERNANDES, Maria Lídia Bueno. Narrativas de crianças sobre a cidade: pensamento estético, política e cidadania. Revista da FUNDARTE. Montenegro, p.01-18, ano 20, № 42, julho/setembro de 2020.

Disponível em: http://seer.fundarte.rs.gov.br/index.php/RevistadaFundarte/index> 30 de setembro de 2020 


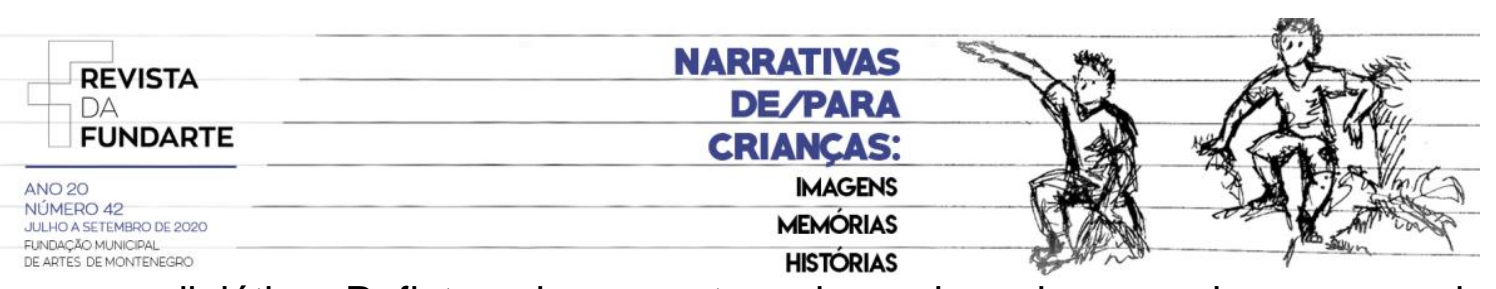

processo dialético. Reflete sobre o protagonismo das crianças e jovens que vivem, se criam e recriam a partir de um paradigma territorial contra hegemônico, em que o território é o espaço vivido, densificado pelas múltiplas relações culturais e sociais. (LEFEBVRE, 1995). Consideram-se as singularidades das crianças e jovens de diferentes Regiões Administrativas do Distrito Federal, levando em conta as especificidades desse território, as relações de poder estabelecidas, bem como as múltiplas formas de apropriação, circulação e transformação do/no território.

Essa abordagem busca compreender os saberes que os diferentes sujeitos trazem sobre sua localidade, em especial, o que as crianças e jovens dizem e pensam sobre esse espaço-tempo, bem como suas experiências ligadas à construção de um sentimento de pertencimento ou a experiências de exclusão e segregação e, como contrapartida a isso, sua experiência de reação, reelaboração.

Os pressupostos teóricos ancoram-se nos estudos sociais da infância, dessa forma reafirma-se o diálogo com autores que se opõem à tentativa de normalização e normatização dessas infâncias e de seus espaço-tempos, ao mesmo tempo em que se acolhem as narrativas sobre suas realidades espaciais, suas expressões sobre formas de ser criança, suas visões de mundo (LOPES; FERNANDES, 2018). Com base na Teoria Histórico-Cultural e da aproximação com os conceitos de vivência (Perejivanie), de meio (Sredá) e de reelaboração criadora (Tvortcheskaia Pererabotka) identifica-se a unidade pessoa-meio (Vigotski, 2010), esta compreensão é corroborada pelo olhar de Massey (2015), Aitken (2014), Harvey (2008), Léfèbvre (1995), Haesbaert (2014) e Santos (2012), ao tratarem das temáticas ligadas ao lugar, ao território, à perspectiva de pertencimento em relação à cidade e para abrir possibilidades de leitura de mundo.

Para tanto, buscou-se olhar para o cotidiano das crianças dos anos iniciais do ensino fundamental, estudantes da Escola Parque 210/211 norte, durante as aulas de Artes Visuais em um período de seis meses. Compreendendo que as representações das crianças estão impregnadas de significados, de sentidos e que, nos discursos, nas falas e nas práticas, há intencionalidades nem sempre objetivas.

BARBOSA, Maria Andreza Costa. FERNANDES, Maria Lídia Bueno. Narrativas de crianças sobre a cidade: pensamento estético, política e cidadania. Revista da FUNDARTE. Montenegro, p.01-18, ano 20, № 42, julho/setembro de 2020.

Disponível em: http://.seer.fundarte.rs.gov.br/index.php/RevistadaFundarte/index> 30 de setembro de 2020 


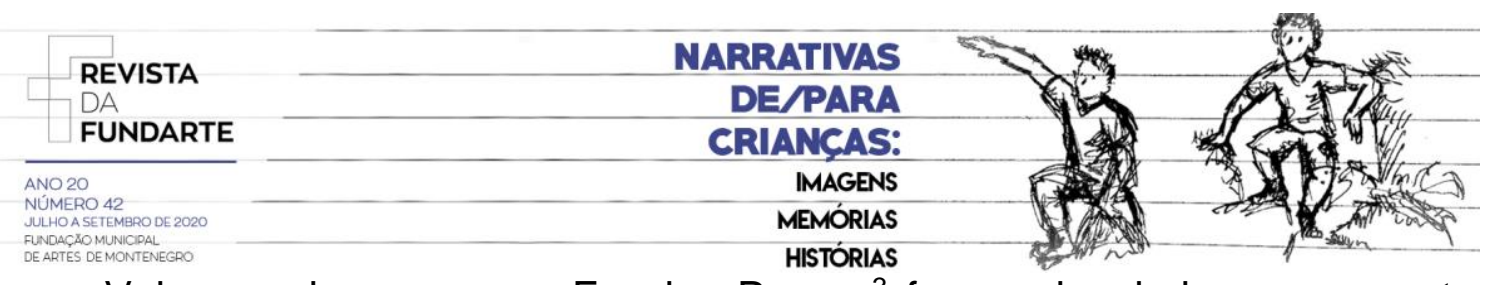

Vale mencionar que as Escolas Parque ${ }^{3}$ foram planejadas como centro de educação, de cultura, esporte e lazer para atendimento às Escolas Classe da vizinhança e para a integração das mesmas, as quais ao receberem esse atendimento são chamadas de Escolas Classe Tributárias, adjetivo que faz analogia a um rio e seus afluentes.

A Escola Parque 210/211 norte está situada no Plano Piloto e recebe estudantes de quatro Escolas Classe Tributárias para a realização de aulas de Arte nas diferentes linguagens: Visuais, Teatro, Música, além da Educação Física, no âmbito da educação de tempo integral. Observa-se que os estudantes são moradores das diversas regiões administrativas do DF.

Cabe ressaltar que a Escola Parque está baseada no ideário de escola pública, laica e democrática e planejada em sintonia com o modelo urbano projetado para Brasília. Nasce com um forte significado, como um sistema educacional inovador para a capital na perspectiva da educação integral e como local de encontro da comunidade, de cultura na cidade e de ensino diferenciado.

Não obstante, por diversas razões de ordem econômica, política e ideológica, este projeto educacional que se inicia em Brasília, com a perspectiva de ser implementado para o restante do país, não chegou a ser desenvolvido. Hoje há apenas algumas Escolas Parque em todo o Distrito Federal com atendimento diferenciado de sua versão inicial.

Contudo, a Escola Parque é considerada, por professores e comunidade, como espaço que guarda a memória da proposta de educação inovadora, de elo entre educação e cultura, com foco no desenvolvimento individual e nos direitos coletivos que marcam a utópica Brasília, sendo vista pelos estudantes como espaço lúdico e de formação nas dimensões física, psicológica, social e cultural.

\footnotetext{
${ }^{3}$ No Plano de Construções Escolares de Brasília, elaborado por Anísio Teixeira em 1960 a cada quatro quadras residenciais haveria uma Escola Parque. A Escola Parque foi planejada com bibliotecas, teatro e quadras esportivas para atendimento aos estudantes das Escolas Classe no contraturno para atividades de arte e educação física e à comunidade para cultura e lazer. No entanto, há atualmente sete Escolas Parque construídas, cinco situadas no Plano Piloto, uma na região administrativa de Ceilândia e outra em Brazlândia.
}

BARBOSA, Maria Andreza Costa. FERNANDES, Maria Lídia Bueno. Narrativas de crianças sobre a cidade: pensamento estético, política e cidadania. Revista da FUNDARTE. Montenegro, p.01-18, ano 20, № 42, julho/setembro de 2020.

Disponível em: http://.seer.fundarte.rs.gov.br/index.php/RevistadaFundarte/index> 30 de setembro de 2020 


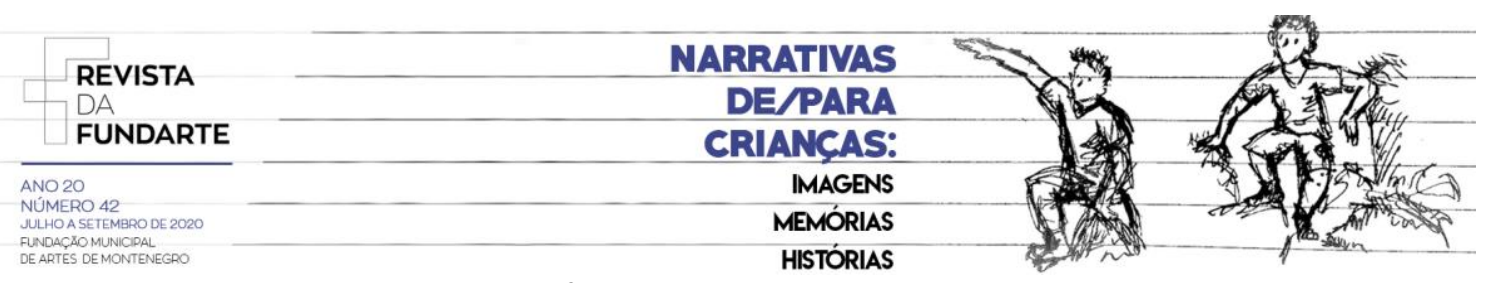

Este espaço de ensino oferece um campo rico para a pesquisa, porque, além de atender a um grande número de estudantes, apresenta como proposta pedagógica o vínculo com a comunidade e com a cidade por meio da cultura. Desse vínculo surge o interesse em investigar como o conhecimento cotidiano e as referências culturais da cidade interferem e se fazem presentes nas elaborações das crianças.

Assim, acessa-se a realidade social e as formas como são desenvolvidas as práticas sociais em suas relações espaciais por meio das narrativas das crianças. $O$ artigo em tela tem como objetivo: a) conhecer o olhar singular das crianças sobre 0 Distrito Federal; b) analisar a elaboração estética das crianças em suas narrativas sobre o território ao transpor os pensamentos e as paisagens em imagens.

A metodologia envolve a observação participante, diálogos com as crianças e elaboração de seus Mapas Vivenciais, que foram realizados por meio de desenho e aquarela sobre o lugar de moradia dos estudantes e seus percursos na cidade. Desse modo, o presente estudo foi guiado pelos caminhos apontados por Ghedin e Franco (2011), ao conceberem a metodologia de pesquisa como "um processo que organiza cientificamente todo o conhecimento reflexivo, do sujeito ao empírico e deste ao concreto, até a organização de novos conhecimentos, que permitam nova leitura/compreensão/interpretação do empírico inicial" (GHEDIN; FRANCO, 2011, p.107).

Este artigo está estruturado da seguinte forma: no primeiro item temos a contextualização da construção de Brasília e a imbricada teia de relações envolvendo o estabelecimento do Distrito Federal, os processos de segregação engendrados, a utopia e a distopia em torno da mudança da capital. No segundo item retratamos a pesquisa, analisamos os dados e dialogamos com os autores que dão sustentação teórica ao trabalho. Por fim, tem-se as considerações finais, em que são desveladas as interpretações infantis envolvendo sua vida na cidade. Assim, concordamos com Sarmento e Pinto quando afirmam que "o olhar das

BARBOSA, Maria Andreza Costa. FERNANDES, Maria Lídia Bueno. Narrativas de crianças sobre a cidade: pensamento estético, política e cidadania. Revista da FUNDARTE. Montenegro, p.01-18, ano 20, № 42, julho/setembro de 2020.

Disponível em: http://.seer.fundarte.rs.gov.br/index.php/RevistadaFundarte/index> 30 de setembro de 2020 


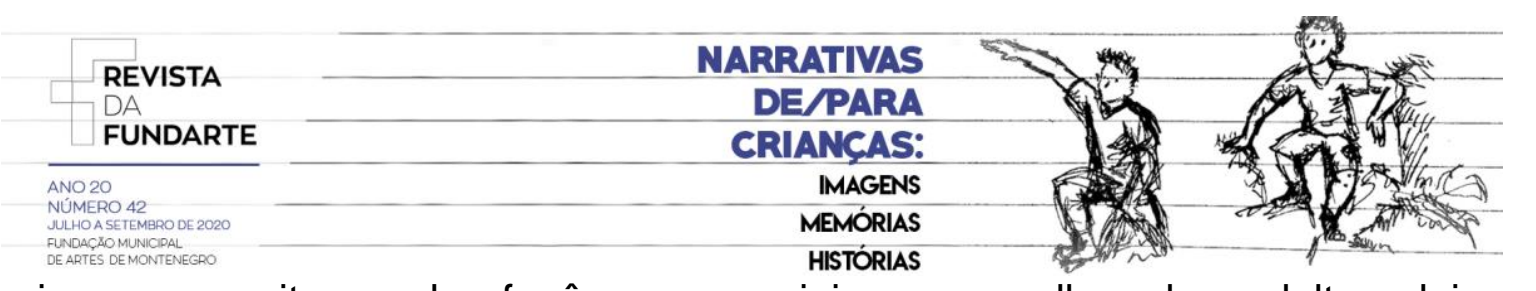

crianças permite revelar fenômenos sociais que o olhar dos adultos deixa na penumbra ou obscurece totalmente" (SARMENTO; PINTO, 1997, p.10).

\title{
$O$ contexto da pesquisa
}

\begin{abstract}
Vista desde el aire, Brasilia es una bella composición: diseñada como un águila, el sector gubernamental se encuentra en lo que sería la cabeza mientras que las áreas residenciales están en las alas. La disposición de los elementos sigue siendo interesante a la altura de un vuelo en helicóptero, donde se observan los blancos edificios oficiales y los grandes bloques de viviendas, colocados alrededor de grandes plazas y extensas zonas verdes. Hasta ahí, todo está bien. (GEHL, 2014, p. 196).
\end{abstract}

Brasília, capital do Brasil, inaugurada em 21 de abril de 1960 nasce como um projeto modernista, que tem como objetivo constituir um espaço urbano diferenciado do convencional, um novo tipo de cidade, inteiramente pública, equilibrada entre as funções de moradia, trabalho, lazer e circulação, seguindo os pressupostos da arquitetura moderna. ${ }^{4}$ A capital emerge como uma proposta de redefinição urbana com a organização e as funções da cidade a partir da lógica de renovação da vida coletiva. De certa forma, podemos dizer que a construção de Brasília significou o ingresso do Brasil na modernidade, relacionada à investida artística e à interferência do Estado na forma como o indivíduo organiza e constrói o seu espaço social.

Não obstante, mesmo imaginada como um projeto de nação, com a expectativa que o espaço urbano planejado pudesse relacionar funcionalidade e fruição e que a arte e a técnica pudessem dar a todos uma vida melhor, Brasília constituiu-se com uma realidade muito diferente do projeto original utópico proposto (CARPINTERO, 1998).

4 O Plano Piloto de Brasília baseia-se nas propostas discutidas e realizadas no Congrés Internacionaux d'Arquitecture Moderne-CIAM o qual representou um importante fórum internacional de discussão sobre a arquitetura moderna, ocorreu entre 1928 a 1960 e contou com a participação de Lúcio Costa e Oscar Niemeyer a partir 1930. Em 1957, Le Corbusier apresenta nesse fórum A carta de Atenas, documento que explicita um planejamento urbano cuja concepção se encontra nas propostas elaboradas para Brasília (HOLSTON,199, p. 37).

BARBOSA, Maria Andreza Costa. FERNANDES, Maria Lídia Bueno. Narrativas de crianças sobre a cidade: pensamento estético, política e cidadania. Revista da FUNDARTE. Montenegro, p.01-18, ano 20, № 42, julho/setembro de 2020.

Disponível em: http://.seer.fundarte.rs.gov.br/index.php/RevistadaFundarte/index> 30 de setembro de 2020 


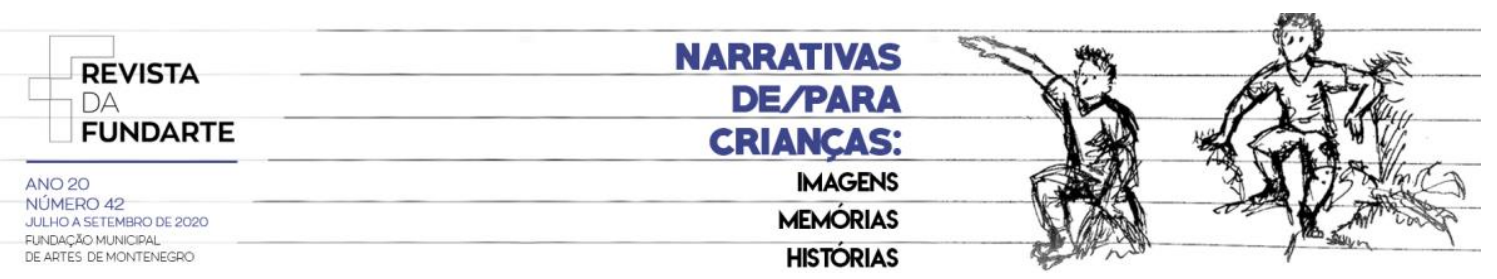

A implantação de Brasília pode ser abordada por diferentes pontos de vista, pois são várias representações que estiveram vinculadas ao seu período de construção. Vale ressaltar a atuação do Estado na produção do espaço e a interiorização da capital do país com vistas à formação de um centro de propulsão política e expansão econômica. Uma das discussões, portanto, é a tomada de posse da região central do país e a modificação de sua natureza no ritmo do capitalismo emergente (VESENTINE, 1986).

Em relação ao projeto urbanístico, como bem mencionam as críticas à cidade, existem ali questões prementes. Uma delas é a questão escalar, ou seja, a macroescala sobrepondo-se à micro, e, com isso, um distanciamento da dimensão humana. Assim é que inúmeras críticas são feitas ao planejamento concebido de cima e de fora (GEHL, 2014).

Pois, como a civitas não poderia ser uma cidade qualquer, configuram-se uma ordem, uma harmonia e uma estética completamente diferentes das demais cidades tradicionais brasileiras. Mas, ao mesmo tempo, essa característica pressupõe a adaptação do morador a uma estética já concebida por um plano rígido e racionalmente elaborado (VESENTINE, 1986).

Entretanto, entre a utopia da cidade planejada para uma nova ordem de acordo com um padrão alcançado na articulação das escalas monumental, residencial, gregária e bucólica para favorecer as funções da cidade moderna, e a realidade de uma cidade que se concretiza entre a "utopia do modernismo e a decadência da modernização" temos as realidades das Regiões Administrativas que extrapolam o denominado "plano piloto". Nas Regiões Administrativas circunvizinhas à Brasília, onde reside cerca de $85 \%$ da população do Distrito Federal, vive-se outra realidade marcada por contradições, já que a massa de trabalhadores da construção civil que veio à Brasília construir o sonho sonhado pelos brasileiros, submetendo-se à jornadas extenuantes de trabalho, com riscos de

\footnotetext{
${ }^{5}$ Título de um trabalho artístico de Thales Noor que retrata Brasília em suas idiossincrasias.
}

BARBOSA, Maria Andreza Costa. FERNANDES, Maria Lídia Bueno. Narrativas de crianças sobre a cidade: pensamento estético, política e cidadania. Revista da FUNDARTE. Montenegro, p.01-18, ano 20, № 42, julho/setembro de 2020.

Disponível em: http://.seer.fundarte.rs.gov.br/index.php/RevistadaFundarte/index> 30 de setembro de 2020 


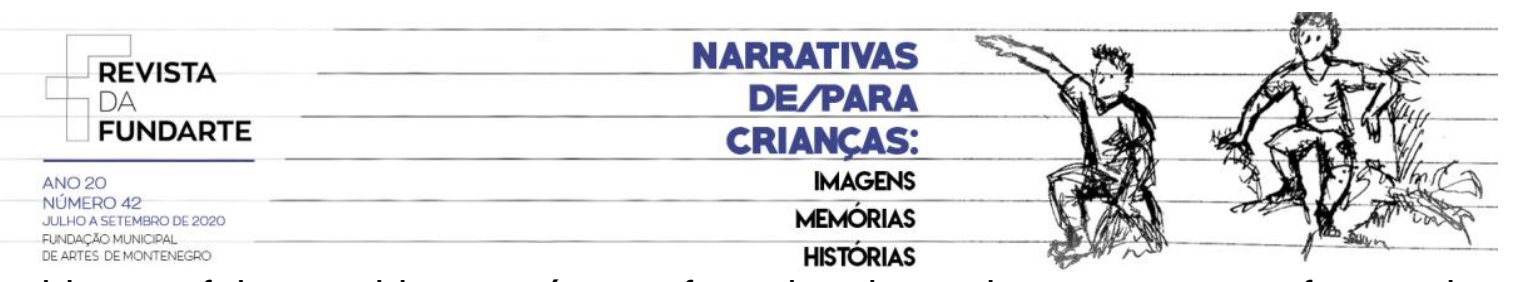

acidentes, foi removida para áreas afastadas do moderno centro, conformando uma cidade poli nucleada e atravessada por desigualdades.

Assim, Brasília configura-se como uma cidade em que o moderno convive com o arcaico de forma explícita, já que é marcada pela segregação espacial e pela periferização, que permitiu a exclusão dos trabalhadores que construíram a capital federal.

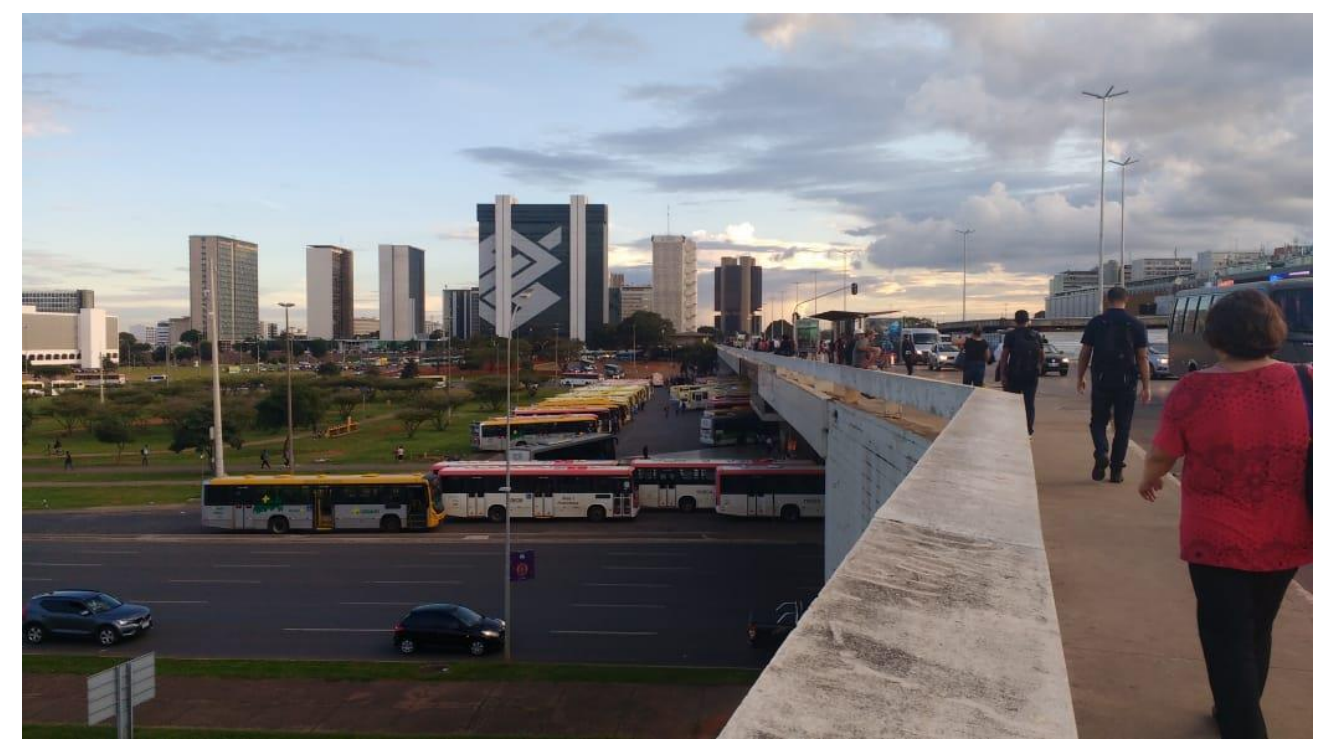

Imagem 1:Brasília em meio aos grandes prédios e avenidas (eixos), vê-se a rodoviária, que recebe um enorme contingente populacional cotidianamente, em um movimento pendular constante. (Fonte: Arquivo da pesquisa)

Nesse sentido, há questões que perpassam o cotidiano da cidade desde a sua inauguração pois, ao pensar a capital federal exclusivamente como Plano Piloto e na lógica racionalizada do projeto, o Estado impôs um distanciamento das classes sociais em nível territorial e de acesso aos bens públicos. Além disso, se a nova ordem passa pela ordem urbana, Brasília, como ação do Estado, preservou as diferenças sociais e econômicas em seu traçado por meio do planejamento, da arquitetura, da dimensão estética e dos aparelhos públicos que são evidentes no Plano Piloto e ausentes na periferia (VESENTINE, 1986).

BARBOSA, Maria Andreza Costa. FERNANDES, Maria Lídia Bueno. Narrativas de crianças sobre a cidade: pensamento estético, política e cidadania. Revista da FUNDARTE. Montenegro, p.01-18, ano 20, № 42, julho/setembro de 2020.

Disponível em: http://.seer.fundarte.rs.gov.br/index.php/RevistadaFundarte/index> 30 de setembro de 2020 


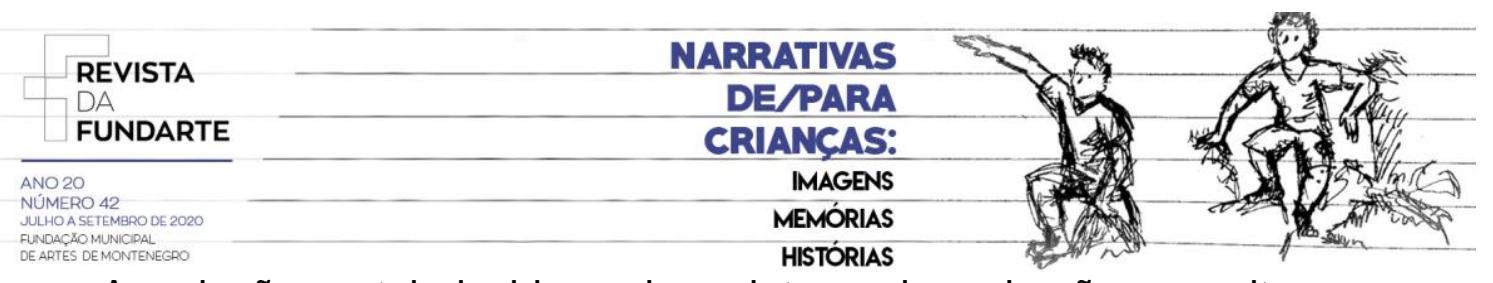

As relações estabelecidas pelo projeto moderno impõem um ritmo e um modo de vida que parecerão distanciados dos indivíduos, um espaço fragmentado, mas definidor dos movimentos da sociedade. Santos (2012), ao tratar da relação tempo/espaço na modernidade, nos explica que o espaço se apresenta como fragmento em um tempo e em uma realidade, dificultando sua reconstrução como unidade.

Contudo, Santos nos diz que, é pelo lugar que podemos compreender as contradições e nos aproximar da realidade, pois o lugar é a permanência e nele se situa a história dos sujeitos. "É pelo lugar que revemos o mundo e ajustamos nossa interpretação, pois, nele o recôndito, o permanente e o real triunfam afinal, sobre o momento, o passageiro, o imposto de fora" (SANTOS, 2012, p. 33).

Assim, para nos aproximar das especificidades desse território e, das múltiplas formas de apropriação e transformação do espaço, buscamos no olhar e na fala das crianças, estudantes da Escola Parque 210 norte, situada no Plano Piloto de Brasília, o que pensam e como refletem sobre a sua cidade.

Compreendendo que a cidade é um lugar do imaginário e de representações que podem se constituir de vários sentidos, porque o imaginário que circula pela cidade é um discurso que produz modos de ver e de ser ou mesmo, nas palavras de Michel de Certeau (2012, p.41) "o elemento urbano que nos faz pensar". Vemos, na cidade, imagens de uma organização cultural e social que engendra uma dimensão estética a qual vivenciamos diariamente.

Entende-se que o pensamento estético está situado na ordem política que é a possibilidade de expressão e compreensão da democracia e da cidadania. Essa dimensão da elaboração estética é discutida por Aitken (2014) como forma de ver e de fazer a cidade onde as práticas sociais, econômicas, culturais, políticas acontecem e estão entrelaçadas. A cidadania, desse ponto de vista, não se insere em uma questão de direitos autônomos e, sim, nessa complexidade de relações.

Ao discutir essas questões, o autor nos fornece elementos para a reflexão sobre os direitos das crianças em viver a cidade, observa-se que em relação às

BARBOSA, Maria Andreza Costa. FERNANDES, Maria Lídia Bueno. Narrativas de crianças sobre a cidade: pensamento estético, política e cidadania. Revista da FUNDARTE. Montenegro, p.01-18, ano 20, № 42, julho/setembro de 2020.

Disponível em: http://.seer.fundarte.rs.gov.br/index.php/RevistadaFundarte/index> 30 de setembro de 2020 


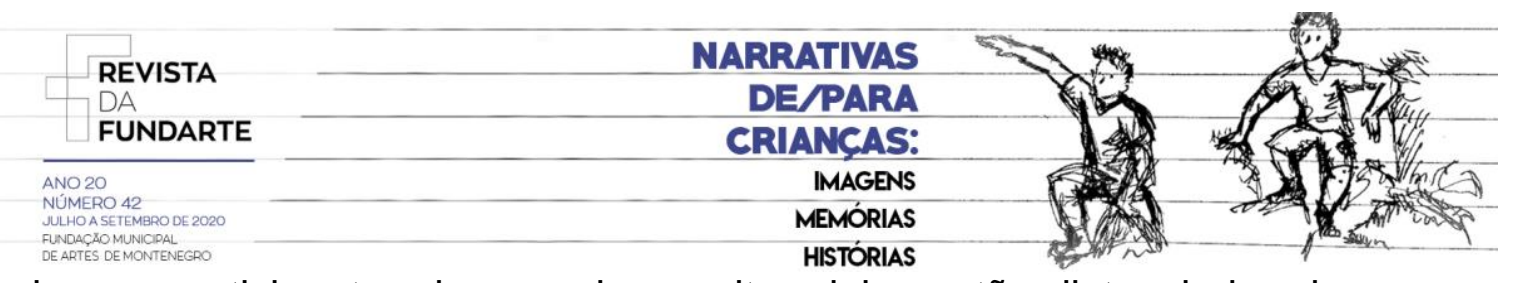

crianças participantes da pesquisa, muitas delas estão distanciadas do acesso aos espaços públicos. Além disso, o autor provoca-nos a pensar na ação política necessária como crítica a esse sistema e à ruptura estética que é vivenciar o urbano e pensar sobre a cidade (AITKEN, 2014).

Afinal, como nos lembram Lopes e Fernandes, as crianças mesmo invisibilizadas nesse sistema e nessa cidade, "são todas crianças territorializadas espacialmente e que vivem o jugo de seus territórios e enraizamentos (econômicos e muitos outros) no embate das políticas econômicas e sociais" (LOPES e FERNANDES, 2018, p. 210).

\section{Narrativas: as crianças e a cidade}

Tendo em vista sermos balizados pelos estudos de Lev Vigostski (2010) e pela teoria histórico-cultural, compreende-se que a imaginação tem, em sua base, as marcas do vivido, da história que foi produzida pelas gerações, ou seja, a cultura produzida pela humanidade e pela experiência presente.

Nesse sentido, os Mapas Vivenciais (Imagens 3, 4 e 5), como proposta de elaboração de desenho e a narrativa individual sobre o lugar, nos possibilitou entrar em contato com a vivência das crianças enquanto processo histórico e reflexivo (LOPES et al, 2016). A casa, a escola e a cidade surgiram como expressão visual dos sujeitos da pesquisa e, ainda, com um conjunto de referências geográficas e culturais.

De certa forma, nos trabalhos analisados foi possível dimensionar a cidade e as possibilidades de cada lugar. Não obstante, não encontramos uma definição de lugar, mas a ideia de lugar relacionado a afeto e a aspectos críticos como as dificuldades para brincar, as distâncias e os perigos. Com isso, não encontramos um único sentido para o conceito de lugar e corroboramos a ideia de Doreen Massey segundo a qual os lugares podem ser conceituados como processos, tendo em vista estarem relacionados às interações sociais (MASSEY, 2000).

BARBOSA, Maria Andreza Costa. FERNANDES, Maria Lídia Bueno. Narrativas de crianças sobre a cidade: pensamento estético, política e cidadania. Revista da FUNDARTE. Montenegro, p.01-18, ano 20, ํo 42, julho/setembro de 2020.

Disponível em: http://.seer.fundarte.rs.gov.br/index.php/RevistadaFundarte/index> 30 de setembro de 2020 


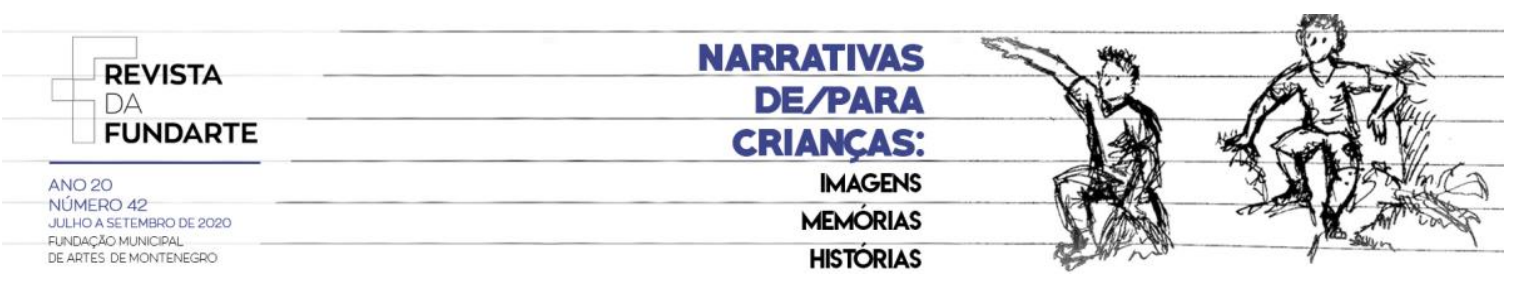

Observamos que os lugares, na concepção das crianças, são singulares, de acordo com suas histórias, sua imaginação e suas vivências. A identidade dos lugares, portanto, não estaria relacionada a uma determinada função ou aos objetos, mas, antes, às significações e aos processos históricos. Como, por exemplo, definir uma identidade para o Plano Piloto? Lugar de desencanto para Gabriel, de cidadania para Luana, de abrigo e, ao mesmo tempo de perigo para Cícero. Brasília aos olhos desses estudantes mostra-se com muitos conflitos e distâncias, entretanto, é o lugar onde está situada a casa e a escola e, onde as crianças vislumbram brechas para a pipa e para a brincadeira de rua.

Podemos, ainda, colocar em questão a identidade e o sentido de pertencimento das crianças em relação ao Plano Piloto enquanto patrimônio histórico e cultural, centro político, lugar de trabalho do servidor público, ponto de interseção das regiões administrativas uma vez que, para muitas crianças participantes desta pesquisa, é um lugar sobre o qual conhecem muito pouco.

Ao conversar sobre Mapas e sobre a cidade, Cícero decidiu desenhar (Imagem 2) a sua melhor referência a sua casa, bela, grande e tranquila, não obstante a complexidade vivida cotidianamente, os pais são catadores, a vida acontece em uma ocupação na Asa Norte, a rotina de vida é incerta e a casa é feita e refeita várias vezes em função da chuva, do vento e das dificuldades inerentes aos processos de exclusão sócio econômica. Contudo, deparamo-nos com a expressão do afeto em relação a sua moradia o que refletiu na seleção das cores e na composição do desenho.

BARBOSA, Maria Andreza Costa. FERNANDES, Maria Lídia Bueno. Narrativas de crianças sobre a cidade: pensamento estético, política e cidadania. Revista da FUNDARTE. Montenegro, p.01-18, ano 20, № 42, julho/setembro de 2020.

Disponível em: http://.seer.fundarte.rs.gov.br/index.php/RevistadaFundarte/index> 30 de setembro de 2020 


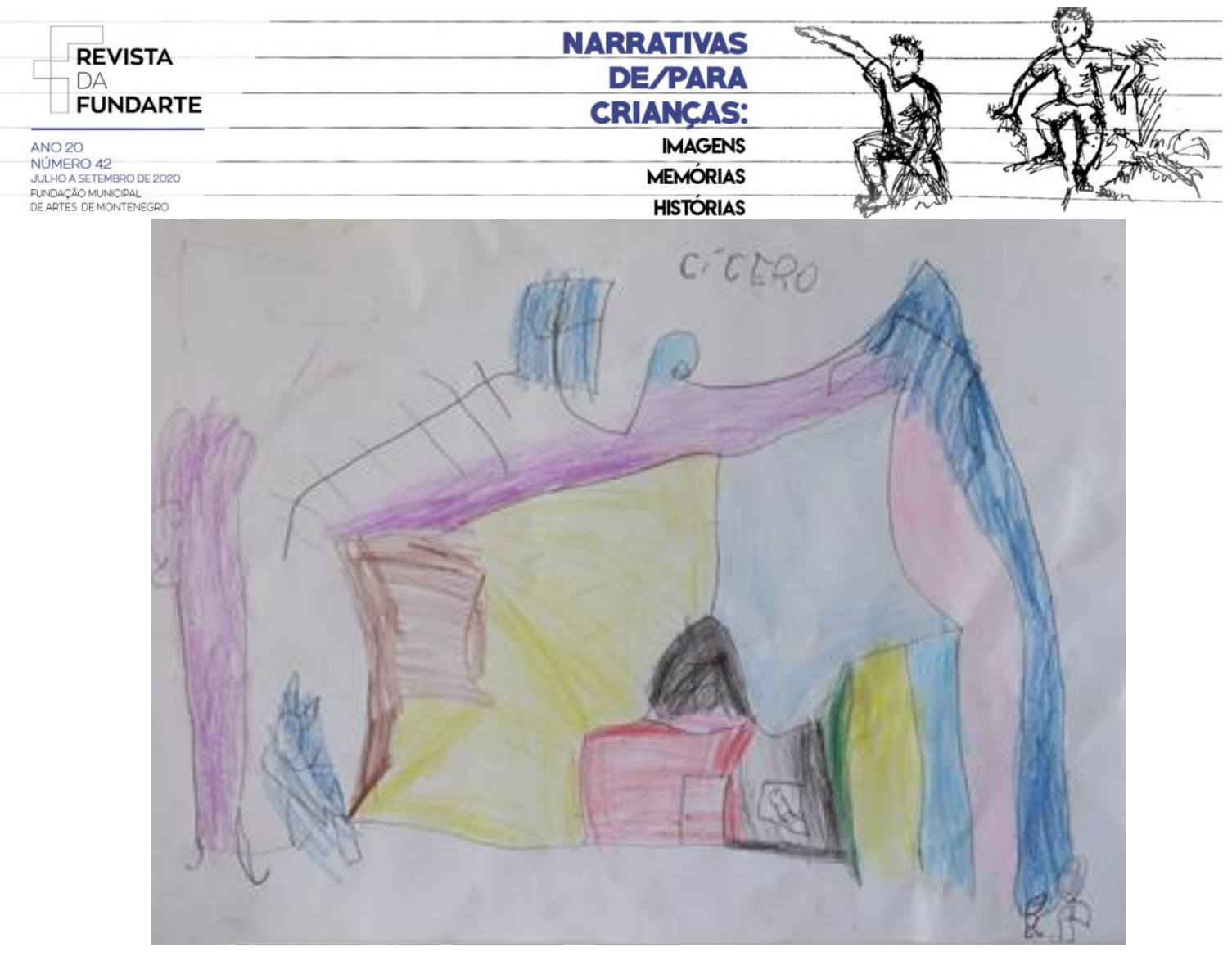

Imagem 2: Desenho de Cícero, aluno do $1^{\circ}$ ano do Ensino Fundamental, morador de uma ocupação situada na Asa Norte/Plano Piloto. (Fonte: Arquivo da Pesquisa)

Composição carregada de imaginação em que Cícero expôs e compartilhou com os colegas os sentimentos que foram vivenciados e sentidos nesse lugar. As brincadeiras com as outras crianças, os perigos da aproximação com a rua, as invenções, a fantasia, a bola, a fogueira e o medo. Sobre Brasília falou das distâncias, a velocidade das avenidas, o tempo gasto com o deslocamento, as passagens subterrâneas, o trabalho dos pais. Ao terminar o desenho Cícero não estava mais interessado em falar sobre a cidade, esteve completamente envolvido neste processo criativo constituído com os elementos de sua realidade e nas novas combinações, que estiveram relacionadas aos elementos afetivos, à imaginação e à interpretação da realidade (VIGOTSKI, 2010).

Gabriel mostra o cotidiano do Setor de Oficinas Norte (Imagem 3), mora em um pequeno apartamento em cima da loja do pai, uma área destinada à indústria, serviços e comércio varejista no Plano Piloto e onde não há aparelhos públicos. Devido as distâncias e as dificuldades de transporte público na cidade, de custo e

BARBOSA, Maria Andreza Costa. FERNANDES, Maria Lídia Bueno. Narrativas de crianças sobre a cidade: pensamento estético, política e cidadania. Revista da FUNDARTE. Montenegro, p.01-18, ano 20, № 42, julho/setembro de 2020.

Disponível em: http://.seer.fundarte.rs.gov.br/index.php/RevistadaFundarte/index> 30 de setembro de 2020 


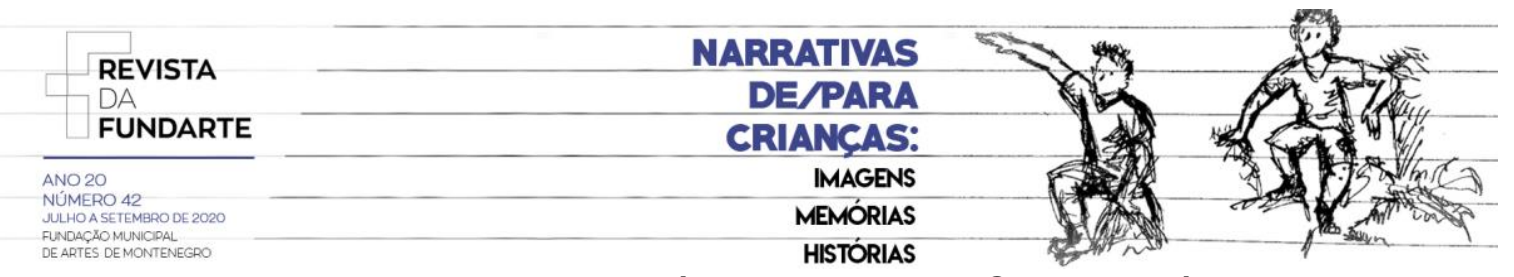

acesso, este setor tornou-se também residencial. Contudo, é um lugar onde há poucas crianças e raros espaços para as brincadeiras.

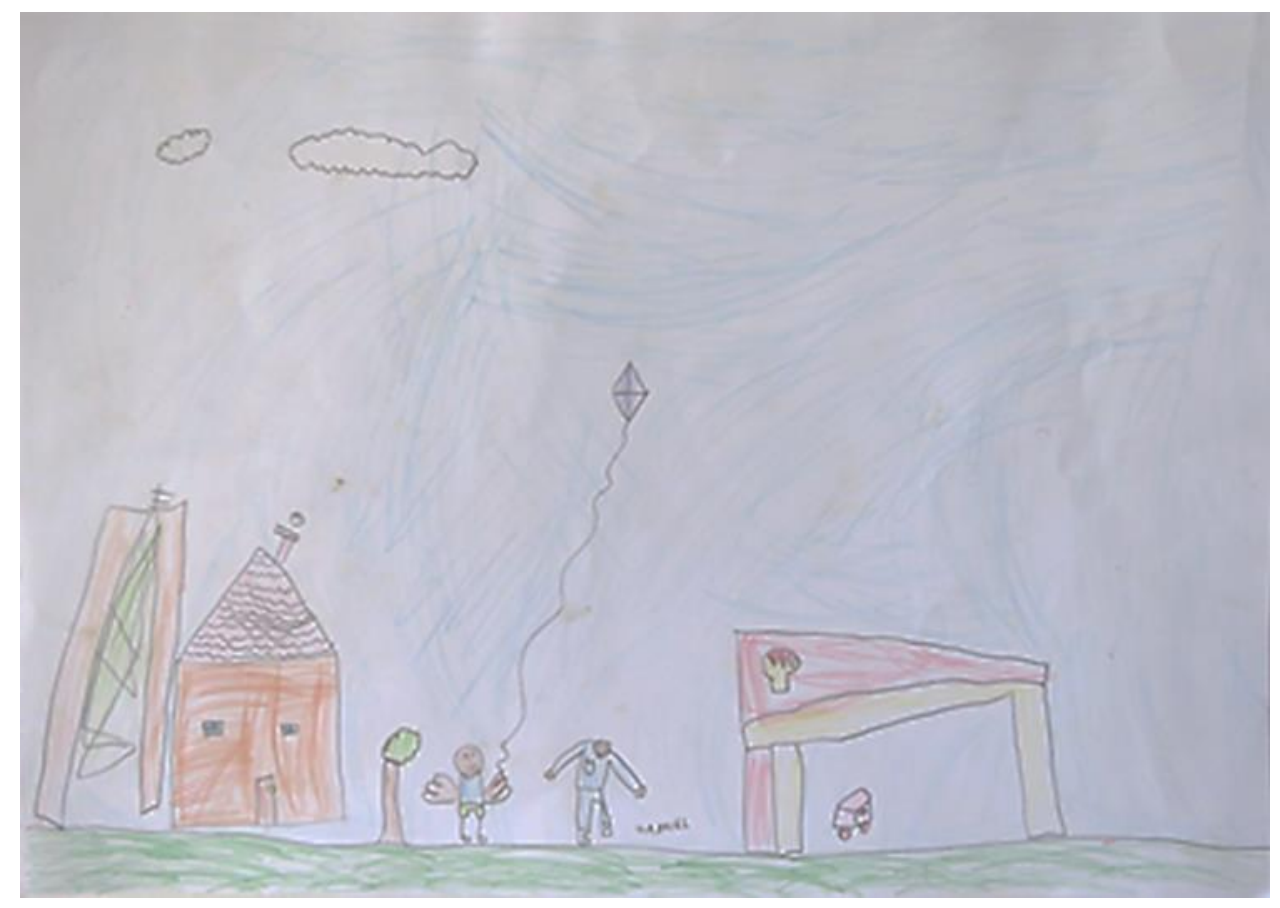

Imagem 3: Desenho de Gabriel, aluno do $2^{\circ}$ ano do Ensino Fundamental, morador do Setor de Oficinas Norte/Plano Piloto. (Fonte: Arquivo da pesquisa)

Mas, Gabriel nos mostra a importância do brincar na rua e a necessidade de um lugar seguro. Assim, interpreta a sua participação na cidade a partir do que lhe é ofertado e de suas relações cotidianas, aspecto que está situado no âmbito da cidadania (AITKEN, 2014). Além disso, o estudante procurou representar o lugar, que se apresentou como categoria interligada às histórias pessoais e ao contexto da cidade. Dessa forma, podemos considerar este trabalho como um desenho (criação) das vivências pessoais sobre o lugar. Representa não só o que existe, mas também o que pode existir.

BARBOSA, Maria Andreza Costa. FERNANDES, Maria Lídia Bueno. Narrativas de crianças sobre a cidade: pensamento estético, política e cidadania. Revista da FUNDARTE. Montenegro, p.01-18, ano 20, № 42, julho/setembro de 2020.

Disponível em: http://.seer.fundarte.rs.gov.br/index.php/RevistadaFundarte/index> 30 de setembro de 2020 


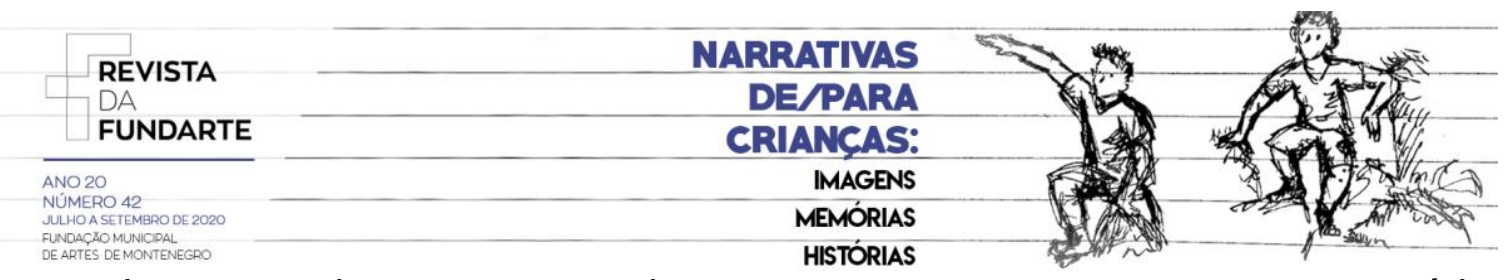

Luana nos leva a pensar sobre tantos momentos em que somos usuários da cidade, como vemos poucas crianças brincando diariamente nas ruas de Brasília, perceber como as quadras e praças do Plano Piloto encontram-se equacionados espacialmente e bem organizados, mas são raras as pessoas vivenciando esses espaços.

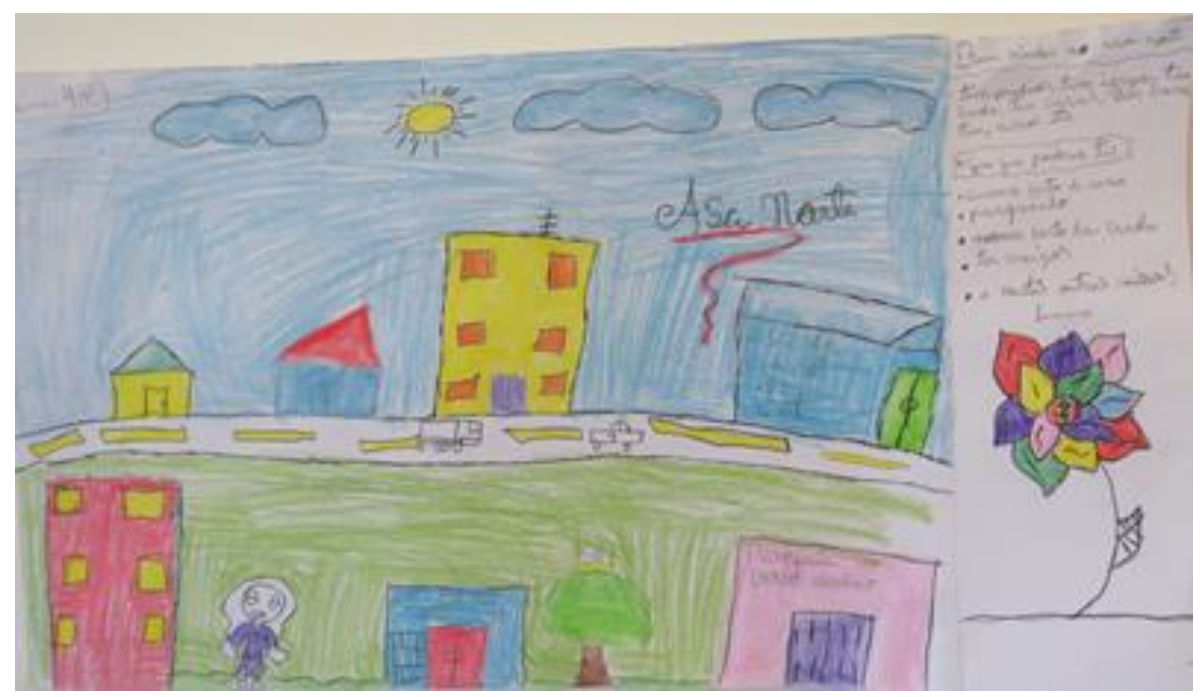

Imagem 4: Desenho de Luana, aluna do 3o ano do Ensino Fundamental, moradora do Plano Piloto SQN 411. (Fonte: Arquivo da pesquisa)

Contudo, Luana brinca na quadra, gostaria de acessar os equipamentos culturais como cinema e teatro com mais facilidade. Nos intensos diálogos durante 0 processo de elaboração do desenho, a estudante mostrou-nos a importância dos aspectos ligados ao componente territorial, da vida social e a cidadania, como acesso a bens e serviços, a sensação de igualdade e a tranquilidade de ser de algum lugar. E, mesmo com poucos amigos por perto, lembra-nos que o Plano Piloto é possibilidade de vivência e de invenção.

Assim, por meio dos desenhos, ficamos diante de diferentes contextos, referências e olhares relacionados à cultura da cidade, elementos estes que constituem a elaboração estética dos estudantes. E, em uma perspectiva históricocultural, podemos analisar estes trabalhos certos de que as ideias sobre o meio envolvem conhecimentos objetivos que são importantes para a elaboração dos

BARBOSA, Maria Andreza Costa. FERNANDES, Maria Lídia Bueno. Narrativas de crianças sobre a cidade: pensamento estético, política e cidadania. Revista da FUNDARTE. Montenegro, p.01-18, ano 20, № 42, julho/setembro de 2020.

Disponível em: http://.seer.fundarte.rs.gov.br/index.php/RevistadaFundarte/index> 30 de setembro de 2020 


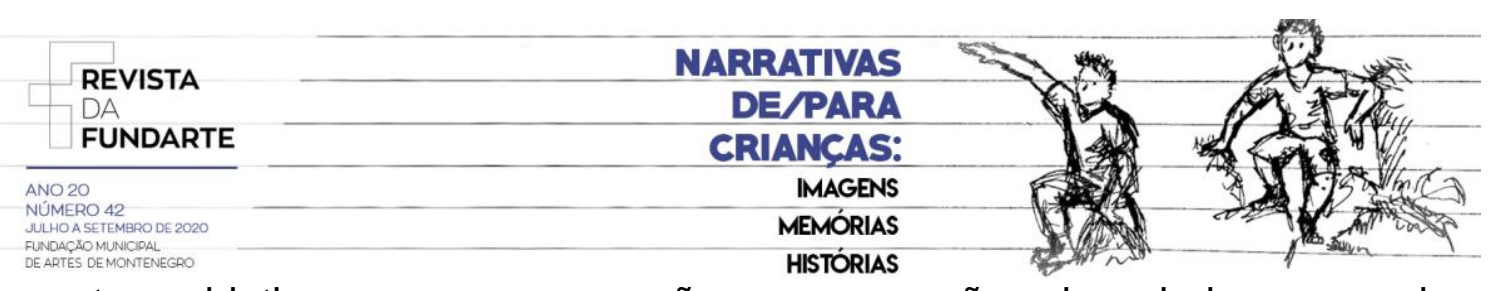

aspectos subjetivos, como a percepção e as sensações vivenciadas nesses lugares (VIGOTSKI, 2010).

\section{Considerações finais}

Constata-se que as impressões e as considerações das crianças estão impregnadas de questões políticas, emocionais, sociais sobre a cidade e sobre a infância nesta cidade. Além disso, o diálogo revelou-se para as crianças como um importante meio de confronto, de descoberta e de liberdade. Tais questões encontram-se interligadas, porque são expressões de vida das crianças.

Existe uma pluralidade de culturas infantis, já que consideramos que cada infância é vivida em um lugar específico e que não existe um único modelo de infância a ser seguido. Afirmamos, também, que há grande influência do território na constituição e desenvolvimento das crianças. Por meio do brincar, das relações entre pares e da vivência em sua cidade elas se descobrem e se desenvolvem e exercem protagonismo. Assim, defendemos que crianças e jovens elegem espaços, apropriam-se deles e os (re)significam a partir de suas lógicas próprias e de seus anseios.

Deve-se ressaltar que o Distrito Federal se constitui como um importante contexto, porque, além de ser um local de moradia ou de estudo do estudante, é o território que inaugurou um projeto urbanístico e arquitetônico diferenciado, cujo desenvolvimento, ao longo de sua história, deu-se de forma bastante complexa. A cidade, contudo, nos provocou e nos fez refletir sobre o cotidiano dos sujeitos dessa pesquisa com atenção às imagens e às referências que se formam por meio da organização espacial, da sociabilidade, da segregação social e espacial, dos deslocamentos, da paisagem e da diversidade cultural.

Assim, a importância em compreender como as crianças estabelecem a relação com a cidade, Plano Piloto e as diferentes regiões administrativas do Distrito Federal, como se identificam com o seu lugar de moradia e com a escola, revelou-se uma questão imprescindível no âmbito do ensino da arte e da educação estética.

BARBOSA, Maria Andreza Costa. FERNANDES, Maria Lídia Bueno. Narrativas de crianças sobre a cidade: pensamento estético, política e cidadania. Revista da FUNDARTE. Montenegro, p.01-18, ano 20, no 42, julho/setembro de 2020.

Disponível em: http://.seer.fundarte.rs.gov.br/index.php/RevistadaFundarte/index> 30 de setembro de 2020 


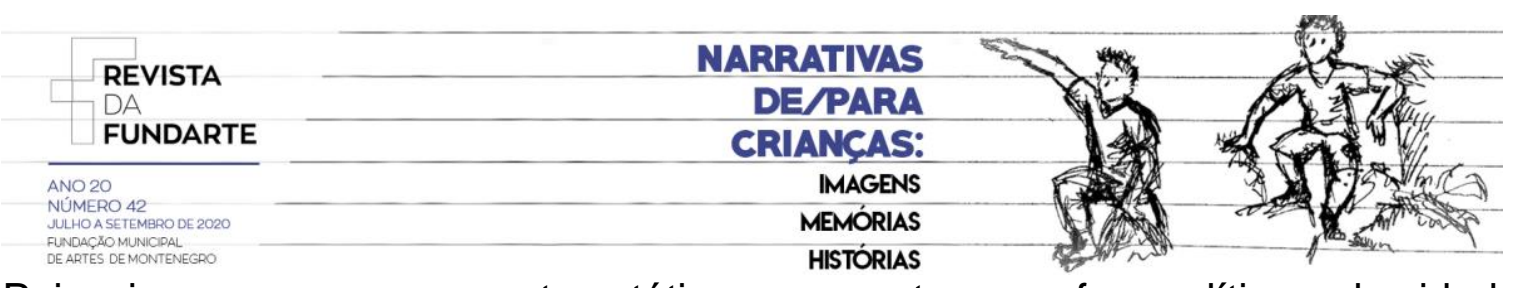

Pois, vimos que o pensamento estético se encontra na esfera política e da cidadania não como uma questão de direitos autônomos e, sim, na complexidade das relações sociais.

Por fim, gostaríamos de concordar com Sarmento e Pinto quando afirmam que "interpretar as representações sociais das crianças pode ser não apenas um meio de acesso à infância como categoria social, mas às próprias estruturas e dinâmicas sociais que são desocultadas no discurso das crianças." (2017, p. 8).

\section{Referências:}

AITKEN, S. Do Apagamento à Revolução: O direito da criança à cidadania/Direito à cidade. Educação e Sociedade, 35(128), 629-996. (jul-set), 2014.

CARPINTERO, A. C. Brasília: Prática e teoria urbanística no Brasil, 1956-1998. Universidade de São Paulo- Tese de Doutorado, São Paulo, 1998.

CERTEAU, M. A. Invenção do cotidiano. Petrópolis: Vozes, 1994.

GHEDIN, E.; FRANCO, M. A. S. Questões de método na construção da pesquisa em educação. $2^{a}$ ed. São Paulo: Cortez, 2011.

GEHL, J. Ciudades para la gente. Buenos Aires: Infinito, 2014.

HAESBAERT, R. Viver no limite: território e multi/transterritorialidade em tempos de in-segurança e contenção. Rio de Janeiro: Bertrand Brasil, 2014.

HOLSTON, J. A. Cidade Modernista: uma crítica de Brasília e sua utopia. $2^{\circ}$ ed. São Paulo: Companhia das Letras, 1993.

LEFEBVRE, H. Lógica formal/lógica dialética. Rio de Janeiro: Civilização Brasileira, 1975.

LOPES, J. J; COSTA, B. M.; AMORIN, C. C. Mapas Vivenciais: possibilidades para a cartografia escolar com as crianças dos anos iniciais. Revista Brasileira de Educação em Geografia, Campinas, v. 6,p. 237-256, 2016.

BARBOSA, Maria Andreza Costa. FERNANDES, Maria Lídia Bueno. Narrativas de crianças sobre a cidade: pensamento estético, política e cidadania. Revista da FUNDARTE. Montenegro, p.01-18, ano 20, № 42, julho/setembro de 2020.

Disponível em: http://.seer.fundarte.rs.gov.br/index.php/RevistadaFundarte/index> 30 de setembro de 2020 


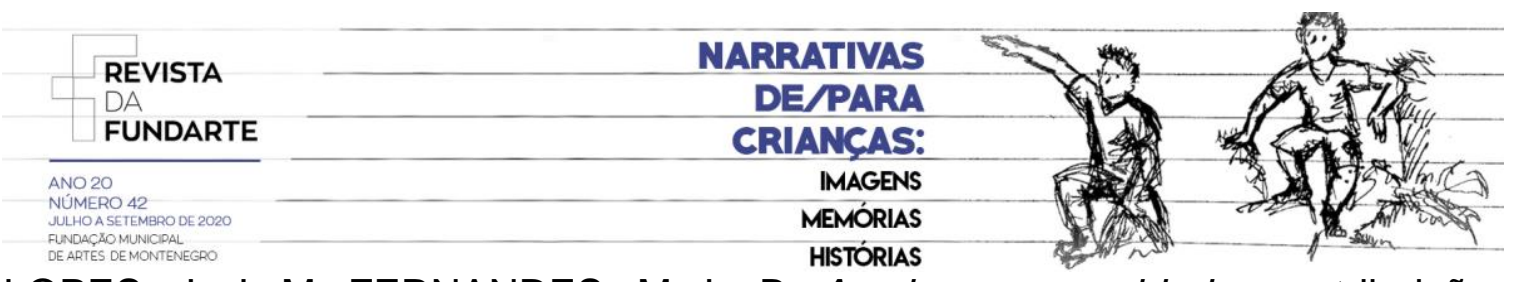

LOPES, J. J. M; FERNANDES, M. L. B. A criança e a cidade: contribuições da Geografia da infância. Educação (Porto Alegre), v. 41, n. 2, p. 202-211, maio-ago, 2018.

MASSEY, D. Um sentido global do lugar. In: ARANTES, A. (Org.). O espaço da diferença. São Paulo: Papirus, 2000.

SARMENTO, M. J.; PINTO, M. As crianças e a infância: definindo conceitos, delimitando o campo. In: PINTO, M., SARMENTO, M. J. (Org.) As Crianças: contextos e identidades. Braga, Centro de Estudos da Criança/Universidade do Minho, p. 9-30, 1997.

SANTOS, M. Pensando o espaço do homem. 5a ed. São Paulo: Edusp, 2012. VESENTINE, J.W. A capital da geopolítica. São Paulo: Ática, 1996.

VIGOTSKI. L.S. Imaginação e Criação na Infância. São Paulo: Ática, 2009.

VIGOTSKI. L.S. Quarta aula: a questão do meio na pedologia. Psicologia USP, São Paulo, p. 681-701, 2010.

BARBOSA, Maria Andreza Costa. FERNANDES, Maria Lídia Bueno. Narrativas de crianças sobre a cidade: pensamento estético, política e cidadania. Revista da FUNDARTE. Montenegro, p.01-18, ano 20, № 42, julho/setembro de 2020.

Disponível em: http://.seer.fundarte.rs.gov.br/index.php/RevistadaFundarte/index> 30 de setembro de 2020 